the sensitive biological communities that live near under-sea mountains, hydrothermal vents and mineral-rich nodules on the sea floor, says David Santillo, a marine biologist and senior scientist at Greenpeace Research Laboratories at the University of Exeter, UK. As well as the physical destruction of habitats, he adds, this type of mining could smother deep-sea species with suspended plumes of sediment. Species could also be disturbed by noise, light pollution and exposure to toxic metals and other chemicals released by the mining.

The severity of such effects depends on several factors, including the nature of the exploited resource and the method of extraction, says oceanographer Cindy Van Dover, director of the Duke University Marine Laboratory in Beaufort, North Carolina. But her biggest concern is the general lack of knowledge about sea-floor processes and the cumulative effects of multiple mining events. "If we get the environmental management wrong, we are unlikely to be able to fix our mistake," she says.

The MIDAS project, which began in November, is receiving $€ 9$ million from the European Union, and includes representatives from industry and non-governmental organizations. "We will try to identify the best ways to monitor before, during and after mining to determine the total impact and recovery of the ecosystems," says Philip Weaver, managing director of Seascape Consultants in Romsey, UK, which is coordinating MIDAS.

Cruises to conduct experiments and sampling at depth form a core part of the project's work. The IFREMER cruise, on the research vessel Pourquoi Pas?, was the first stage of a two-year experiment to test the effects of sulphide plumes. The research team weighed mussels found around hydrothermal vents at a depth of 1.7 kilometres and assessed their general health. Next year, they will return and mimic the effects of particle plumes on the mussels, monitoring their reactions - for instance, death, migration or increased numbers - with temperature sensors and cameras. The results of the tests will then be studied on shore.

A second MIDAS study is currently simulating potential effects on marine life in the shallow waters of Portman Bay off the coast of southeastern Spain. An onshore mining facility dumped waste into the waters there for three decades, and the researchers want to assess how the waste affected the underwater fauna. "We want to see how metal-loaded plumes behave - how far they spread, how long it takes for them to settle and so on," says marine geoscientist Miquel Canals Artigas of the University of Barcelona in Spain, who is leading the expedition.

MIDAS will submit its report to the European Commission in November 2016.

\title{
NEUROSCIENCE
}

\section{Teen drug use gets supersize study}

\section{US government programme will examine 10,000 adolescents to document effects on developing brains.}

\section{BY SARA REARDON}

W hen the states of Colorado and Washington voted to legalize marijuana in 2012, the abrupt and unprecedented policy switch sent the US National Institute on Drug Abuse (NIDA) into what its director Nora Volkow describes as "red alarm". Although marijuana remained illegal for people under the age of 21, the drug's increased availability and growing public acceptance suggested that teenagers might be more likely to try it (see 'Highs and lows'). Almost nothing is known about whether or how marijuana affects the developing adolescent brain, especially when used with alcohol and other drugs.

The new laws, along with advances in brainimaging technology, convinced Volkow to accelerate the launch of an ambitious effort to follow 10,000 US adolescents for ten years in an attempt to determine whether marijuana, alcohol and nicotine use are associated with changes in brain function and behaviour.

At a likely cost of more than US\$300 million, it will be the largest longitudinal brain-imaging study of adolescents yet. Researchers are eager to study a poorly understood period of human development - but some question whether it is possible to design a programme that will provide useful information about the effects of drugs.

"It's definitely an idea that's overdue," says Deanna Barch, a psychologist at Washington University in St. Louis, Missouri. "The downside is it's a lot of eggs in one basket."

The exact design of the programme is still in flux. In May, NIDA held a planning meeting with the National Institute on Alcohol Abuse and Alcoholism, the National Cancer Institute

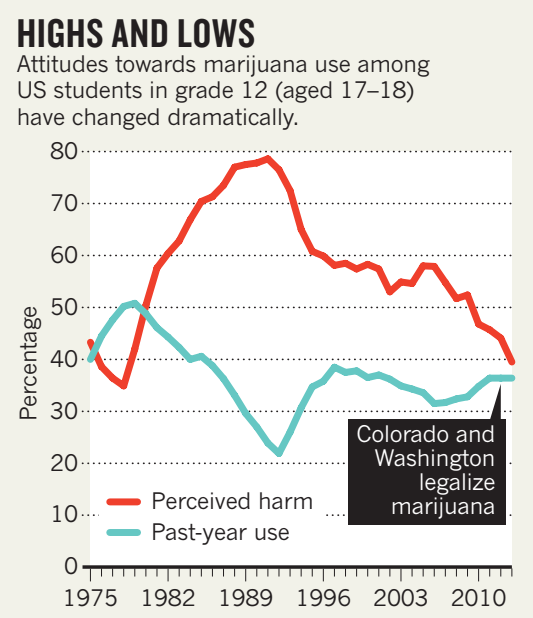

and the National Institute of Child Health and Development (NICHD), which will help to fund the project. The partners decided to recruit participants at the age of ten. Roughly every two years, researchers will image the children's brains, perform psychiatric and cognitive tests, and examine factors such as genetics and environmental exposures.

To enlist enough participants likely to use drugs, the study will recruit largely from highrisk groups, such as children of low socioeconomic status or those whose parents use drugs. Volkow says that the group plans to seek input from colleagues at November's Society for Neuroscience meeting in Washington DC before recruiting researchers for the programme.

Hugh Garavan, a psychPNFHst at the University of Vermont in Burlington, says that there is much to recommend such an analysis.

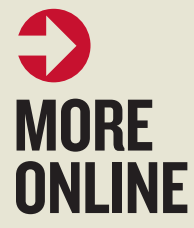

TOP STORY

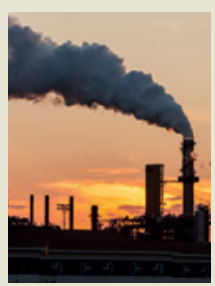

Canada-US oil pipeline could significantly increase emissions go.nature.com/ jcgw9n

\section{MORE NEWS}

- Multiple genes linked to post-traumatic stress disorder go.nature.com/anfirh - Anxiety drug helps boost survival of certain fish species go.nature.com/vbkxqg - Origami robot folds itself in 4 minutes go.nature.com/swqnz7 
- He and his colleagues reported in July - on the basis of a study of 692 European teenagers - that they had identified brain structures and activity patterns that could predict with around $70 \%$ accuracy which 14-year-olds would become binge drinkers by the age of 16 (R. Whelan et al. Nature http://doi.org/t5t; 2014).

A larger study such as NIDA's is the obvious next step, he says, because it will help researchers to account for the myriad environmental and genetic factors that influence development. "I can anticipate this becoming a landmark study," he adds.

Even if the larger human study does not reveal new information about the effects of drugs, it will certainly shed light on the normally developing brain, says Lisa Freund, a developmental psychologist at the NICHD. Volkow says that NIDA plans to make all trial data available to researchers, which could inspire further studies.

But recruiting and retaining so many participants will be challenging, requiring researchers to win the trust of children and their families and to ensure that participants are not burdened by the drug tests and brain scans. The scientists will also need to be flexible in the face of rapidly improving brainimaging techniques, says Terry Jernigan, a cognitive scientist at the University of California, San Diego. Whatever technology is chosen is likely to be obsolete by the study's end, she cautions; upgrading technology haphazardly could make it difficult to compare data across years or study sites. Researchers could use both new and old imaging methods during transition periods, but that could quickly drive up costs.

Others question whether enough is known about the developing brain to identify the mechanisms underlying certain specific conditions. Some studies have linked adolescent use of marijuana to psychosis and to onset of schizophrenia in those at risk, but it is unclear whether this is the case - and if so, whether the drug is a trigger or the teenagers are self-medicating. Because researchers cannot control the drug's timing and dosage, it will be hard to resolve that question in relation to what is happening in the brains of participants who develop psychosis.

"It's almost impossible to establish direct causality" in such cases, Volkow says. Yet she hopes that the NIDA study's huge sample size will reveal broader clues, such as differences in brain structure between drug users and non-users. The institute is considering running a parallel brain-imaging study on non-human primates to help to address this.

B. J. Casey, a psychologist at Cornell University in New York City, hopes that NIDA will address the concerns raised by scientists. "Once you start something like this, it's hard to stop even if the outcomes aren't telling, because people are so invested," she says.

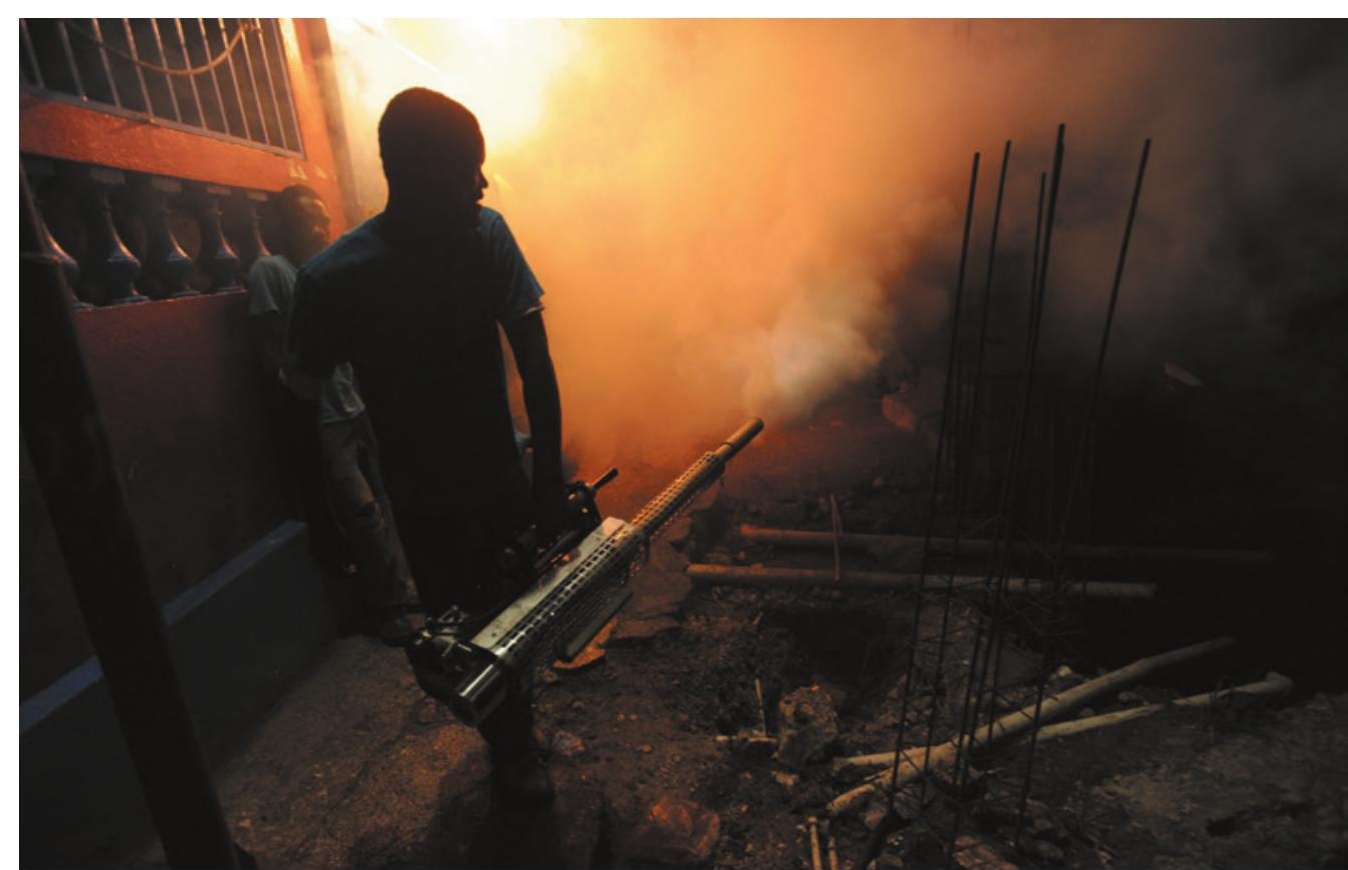

A worker sprays insecticide in Haiti to fight mosquitoes that carry chikungunya and other diseases.

\title{
INFECTIOUS DISEASE
}

\section{US assesses virus of the Caribbean}

\author{
Researchers warn that a change of mosquito host could \\ accelerate spread of chikungunya across the Americas.
}

\section{BY ALESZU BAJAK}

I $n$ the past few months, passengers at North American airports have been warned that travel to the Caribbean might result in an unwanted souvenir. The first outbreak of chikungunya virus in the Western Hemisphere began in the French part of the Caribbean island of St Martin in December and has spread rapidly around the region, infecting more than 500,000 people.

Since then, at least 480 travellers have returned to the United States with the mosquito-borne disease, raising concerns that an insect biting one of those people would spark a US chikungunya outbreak. Yet so far, only four locally acquired cases have been confirmed in the country, all in southern Florida. The virus has gained more of a foothold in Central and South America: authorities have confirmed 174 cases of locally transmitted disease in El Salvador, Panama, Costa Rica, Venezuela and the Guianas (see 'Tropical transfer').

For now, the Caribbean strain of chikungunya does not seem likely to expand into the rest of the Western Hemisphere, mostly because it is spread by the tropical mosquito Aedes aegypti. However, several major chikungunya outbreaks have been fuelled by a specific mutation of the virus that makes it more suited to transmission by a different species of mosquito - a scenario analysed by Carrie Manore, a mathematical epidemiologist at Tulane University in New Orleans, Louisiana, and her colleagues. They report that genetic changes in the virus could propel chikungunya deep into North and South America (C. A. Manore et al. J. Theor. Biol. 356, 174-191; 2014). The insect that could cause the damage is the Asian tiger mosquito (Aedes albopictus), which has been expanding worldwide for the past two decades and taking diseases such as chikungunya and dengue with it (see Nature 489, 187-188; 2012).

Chikungunya was first detected in the 1950s in East Africa. It causes fever, severe joint pain and, in rare cases, death. Most people recover within a week, but painful arthritic symptoms can linger for months.

The Caribbean is fertile ground for the 